\title{
Seismic assessment of a vernacular rammed earth building
}

\author{
Camilla Librici \\ University of Minho, Guimarães, Portugal
}

Daniel V. Oliveira, Rui A. Silva

ISISE, University of Minho, Guimarães, Portugal

Contact: danvco@civil.uminho.pt

\begin{abstract}
Rammed earth constructions represent a valuable cultural heritage of vernacular architecture, whose significance has acquired even more importance in the last years with the renovated interest for this sustainable building technique. The aim of this work is to develop a FEM model typologically representative of a Portuguese vernacular rammed earth construction in order to characterize numerically its seismic performance and raise awareness about the level of improvement introduced by two compatible strengthening techniques: textile reinforced mortar (TRM) and a ring beam applied at the top of the walls.
\end{abstract}

Keywords: rammed earth; seismic assessment; pushover analysis; retrofitting; TRM

\section{Introduction}

Raw earth is used as building material since ancient times. The oldest permanent earthen houses known were found in Çatal Huyuk (Turkey) and Jericho (Israel), around $6000 \mathrm{BC}$, but archaeological evidences related to the use of earth as building material were also found in Egypt, Iraq, Pakistan, Ancient China and Peru [1].

The earth construction concept includes several building techniques, presenting different constructive features and depending on aspects mainly related to the properties of the local soil [2]. Rammed earth is a vernacular construction technique that consists in compacting moist earth by layers inside a temporary formwork in order to build solid monolithic walls. The use of a formwork differentiates this technique from others earth construction techniques [3].
Rammed earth constructions represent a valuable part of the world vernacular heritage, considering their cultural value and environmental compatibility. The conservation of this built heritage assumes an urgent need due to its weak structural properties, mainly against seismic actions, whose effects can severely affect the existing structures leading to partial or total collapse of earthen buildings [4].

In general, as long as the mechanical behaviour is concerned, the material shows a relatively acceptable response in compression, but really poor performance in tension and shear. Earthen materials show a compressive strength normally in between 1 and $4 \mathrm{MPa}$, depending on several factors such as particle size distribution and the construction technique. It is important to highlight the nonlinear behaviour of the material, starting from low values of stress, and its typical brittle of failure [5]. 
In general, the lack of scientific research lead to the absence of standards to assess existing rammed earth constructions. An additional challenge in the assessment of the seismic capacity of this material is the awareness of its structural properties are around 20 times lower than concrete or baked brick [6].

Several parameters must be considered when designing a retrofitting intervention. Above all, the chemical, mechanical and physical compatibility of the new material with the original one must be respected [7]. Traditional techniques include the introduction of external buttresses or tie-rods, methods that can still be valuable to confer punctual reinforcement to structural elements, while respecting the original asset of the construction [4] [8].

Given the poor performance of rammed earth constructions against seismic actions, innovative techniques are nowadays under study to strengthen existing buildings and to achieve a better structural capacity against earthquakes [8].

This paper is focused on the seismic assessment of rammed earth constructions. A typical vernacular rammed earth construction from Portugal has been modelled and its seismic performance has been assessed by means of pushover analyses. Suitable strengthening techniques were considered and its performance is also reported.

\section{Modelling of a traditional rammed earth construction}

\subsection{Typical vernacular rammed earth construction in Portugal}

The Portuguese taipa dwelling is usually a onestorey building of small dimensions with a principal longitudinal direction and a secondary transversal one with a shorter length. Materials other than earth are usually included in the construction, such as thick stone plinths and timber frames, with tier gable roofs and timber lintels to reinforce openings. An example of a typical rammed earth construction from Alentejo is presented in Figure 1.

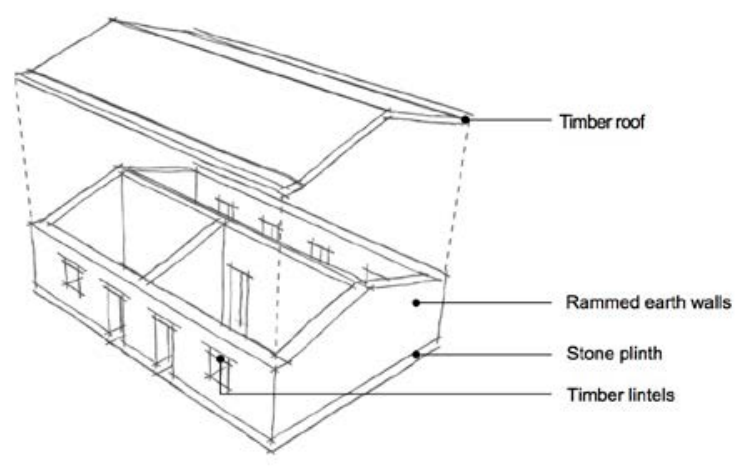

Figure 1. Typical architectural configuration

\subsection{Geometry and mesh}

The building selected as case study has the plan dimensions of $8 \mathrm{~m}$ by $12 \mathrm{~m}$ with wall thickness of $0.5 \mathrm{~m}$. This rammed earth building was modelled using a macro-modelling approach, where the walls are assumed to have a monolithic behaviour and the corners are fully connected.

Three-dimensional brick elements of 20 nodes (CHX60 elements) were used to model the rammed earth, the stone masonry plinth, the lintels of the openings and a concrete ring-beam (for the strengthened model only) [9]. Four elements were used in the thickness of the walls. This division results from what is considered a compromise between the size of the model and the capacity of the model in capturing the out-of-plane behaviour. The nodes at the base of the model were constrained in all directions. The load of the roof was imposed to the load bearing walls. It is worth to note that the model is symmetric with relation to its longitudinal axis.

\subsection{Material properties}

The Total Strain Rotating Crack Model (TSRCM) was used assuming isotropic behaviour. The TSRCM assumes that the crack direction rotates with the principal strain axes.

The tension softening function was selected as exponential and the compressive function to represent the crushing behaviour was assumed as multi-linear, according to recent studies on the FEM modelling of rammed earth wallets [5] [10], see Figure 2. The material properties adopted are listed in Table 1. 


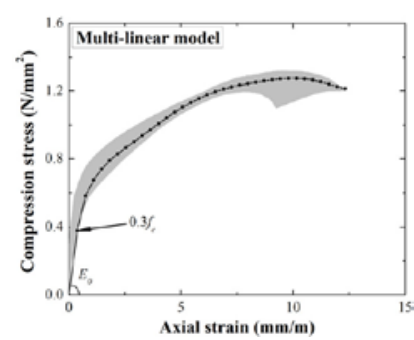

Figure 2. Nonlinear constitutive laws for rammed earth: (a) compression (multi-linear); (b) tension (exponential) [10]

Table 1. Material properties assigned to the materials

\begin{tabular}{c|c|c|c|c|c|c}
\hline \hline & $\begin{array}{c}E \\
{[\mathrm{MPa}]}\end{array}$ & $\begin{array}{c}\mathbf{v} \\
{[-]}\end{array}$ & $\begin{array}{c}\mathbf{f}_{\mathbf{c}} \\
{[\mathrm{MPa}]}\end{array}$ & $\begin{array}{c}\mathbf{f}_{\mathbf{t}} \\
{[\mathrm{MPa}]}\end{array}$ & $\begin{array}{c}\mathbf{G}_{\mathbf{f c}} \\
{[\mathbf{N} / \mathbf{m m}]}\end{array}$ & $\begin{array}{c}\mathbf{G}_{\mathbf{f t}} \\
{[\mathbf{N} / \mathbf{m m}]}\end{array}$ \\
\hline Stone & 1500 & 0.20 & 3.00 & 0.15 & 2.00 & 0.05 \\
\hline $\begin{array}{c}\text { Rammed } \\
\text { earth }\end{array}$ & 500 & 0.27 & 1.30 & 0.05 & 2.00 & 0.05 \\
\hline Timber & 10000 & 0.20 & - & - & - & - \\
\hline \hline
\end{tabular}

\section{Pushover analysis of the unstrengthened model}

\subsection{Dynamic properties}

Due to the lack of a horizontal diaphragm (both in in reality and in the model, as the roof was not modeled), the first modes do not contribute much in terms of effective modal mass. Mode $2\left(T_{2}=\right.$ $0.102 \mathrm{sec})$ and mode $5\left(T_{5}=0.075 \mathrm{sec}\right)$ vibrate in the transversal direction ( $Y$ direction) mobilizing an effective modal mass of $12.5 \%$ and $17.6 \%$, respectively. In turn, mode $8 \quad\left(T_{8}=0.062 \mathrm{sec}\right)$ vibrates in the longitudinal direction ( $\mathrm{X}$ direction) mobilizing an effective modal mass of $42.1 \%$.

\subsection{Pushover analysis (+X direction)}

A pushover analysis was performed in the longitudinal positive direction, see Figure 3 . The most damaged and stressed areas are the connections between the longitudinal and the transversal walls, especially the most external one in the $+X$ direction. The maximum load coefficient reached was 0.89 , for a top longitudinal displacement of $4.1 \mathrm{~mm}$.

\subsection{Pushover analysis (-X direction)}

The main results for the pushover analysis in the longitudinal negative direction are illustrated in
Figure 4, where a peak load coefficient of 0.91 and the corresponding displacement of $9.6 \mathrm{~mm}$ were observed. Although the load capacity is basically the same of the positive direction, the displacement is much larger due to the existence of a door opening in the middle longitudinal wall.

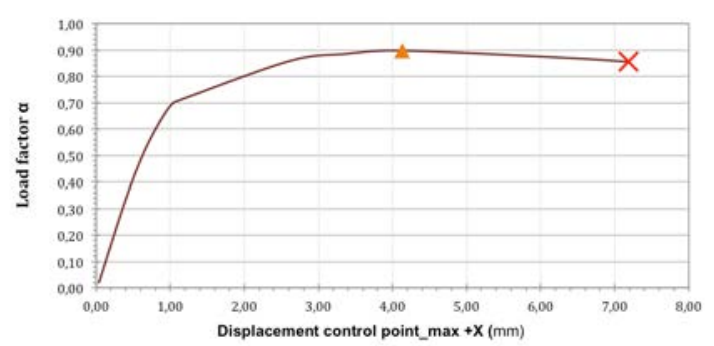

(a)
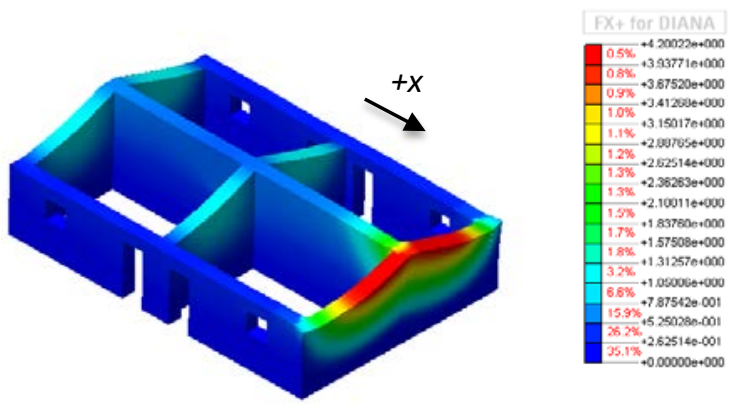

(b)

Figure 3. Pushover results for the $+X$ direction: (a) forcedisplacement curve; (b) displacements at peak load

\subsection{Pushover analysis ( $Y$ direction)}

The nonlinear static analysis was also performed in the $+Y$ direction, see Figure 5. The results, as expected from the geometry of the building, point out that this is the less stiff direction, with a maximum load factor of 0.87 and a corresponding displacement of $17.7 \mathrm{~mm}$, far higher than the peak displacement along the $X$ direction at the maximum load factor.

The comparison of the three capacity curves of the pushover analyses along the $+X,-X$ and $Y$ directions, displayed in Figure 6 , shows that the asymmetry in the $\mathrm{X}$ direction becomes evident only for a high load level, being this direction the stiffer and slightly more resistant one. 


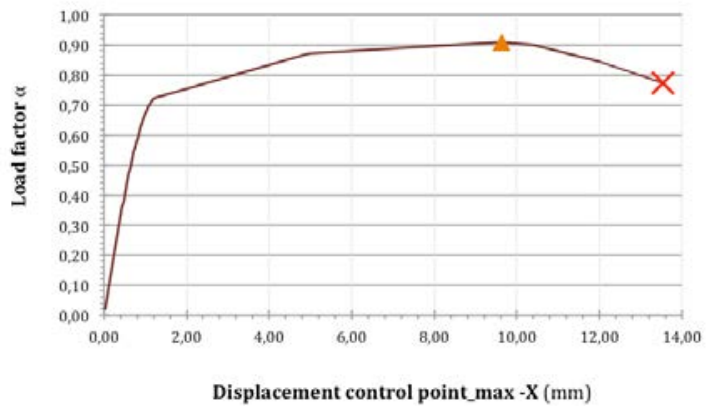

(a)

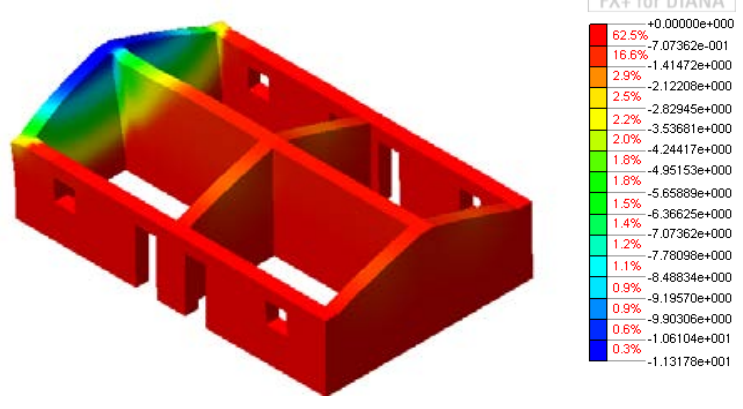

(b)

Figure 4. Pushover results for the $-X$ direction: (a) forcedisplacement curve; (b) displacements at peak load

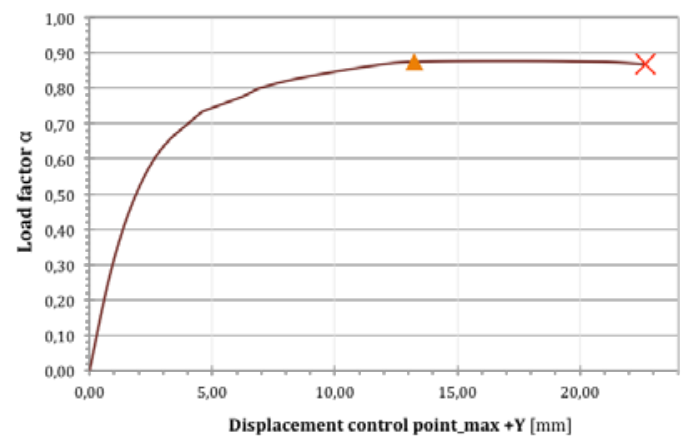

(a)
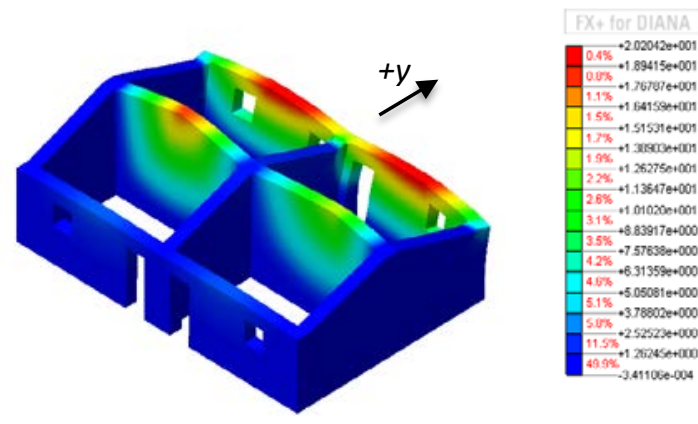

(b)

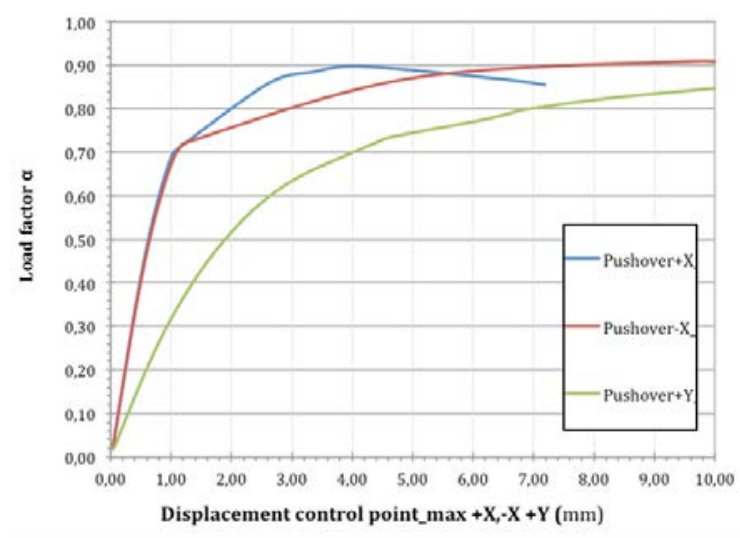

Figure 6. Comparison of the three pushover curves

\section{Pushover analysis of the strengthened model}

The strengthening option presented in this paper comprises the inclusion of a reinforced concrete ring beam on the top of all walls, aiming at conferring a better box behaviour, and the application of compatible reinforced coatings (TRM) at both sides of the rammed earth walls, in order to increase both their general in-plane and out-of-plane behaviour.

As the detailed numerical modelling of the TRM strengthening technique would require a huge computational effort, an easier still acceptable way to evaluate its contribution is to increase certain properties of the original materials by a certain factor. In this work only the tensile parameters were increased to reflect the presence of the reinforced coatings. The tensile strength of the stone masonry and rammed earth were doubled, reading now $0.30 \mathrm{MPa}$ and $0.10 \mathrm{MPa}$, respectively. As for the mode 1 fracture energy, the stone masonry value was also doubled, reading $0.10 \mathrm{~N} / \mathrm{mm}$, while a perfect elastic-plastic behaviour was assumed for rammed earth, with an ultimate tensile strain of $6 \%$.

It is worth to note that the adoption of advanced modelling strategies for the TRM technique without the effective possibility of a reliable validation against experimental results (which still do not exist) is not advisable, and would additionally bring more uncertainty to the analysis.

Figure 5. Pushover results for the $+Y$ direction: (a) forcedisplacement curve; (b) displacements at peak load 


\subsection{Dynamic properties}

The increment in stiffness due to the introduction of the ring beam causes obviously a reduction of the vibration periods. Mode $1\left(T_{1}=0.063 \mathrm{sec}\right)$ and mode $8\left(T_{8}=0.044 \mathrm{sec}\right)$ vibrate in the transversal direction mobilizing an effective modal mass of $52.5 \%$ and $8.4 \%$, respectively. As for the longitudinal direction, mode $3 \quad\left(T_{3}=0.057 \mathrm{sec}\right)$ mobilizes an effective modal mass of $58.5 \%$. The effective modal masses associated to the most relevant vibration modes are now clearly higher due to the stiffening effect of the ring beam.

\subsection{Pushover analysis (+X direction)}

The pushover analysis was performed in both positive and negative directions. As the structural behaviour along the $-\mathrm{X}$ direction is very similar to the one observed along the $+X$ direction, only this latter is discussed herein.

The intervention improved the behaviour of the structure by increasing the maximum load factor in the positive direction from 0.89 to 1.87 with a $40 \%$ decrease in terms of displacement (from $4.1 \mathrm{~mm}$ to $2.5 \mathrm{~mm}$ ), see Figure 7, as the ring beam effectively limits top displacements, thus the drifts.

The walls along the $X$ direction develop an in-plane behaviour while the transversal walls act as restraints as the ring beam provides them with a greater resistance to out-of-plane failure. The tensile principal stresses concentrate at the bottom of the walls and also close to the openings, indicating cracking of the material, Figure $7(\mathrm{c})$.

\subsection{Pushover analysis (+Y direction)}

The pushover analysis along the "weaker" $\mathrm{Y}$ direction was carried out just along the positive direction due to structural symmetry. The most relevant results are given in Figure 8 . It is shown that the introduction of the strengthening improved the seismic behaviour, with an ultimate load factor of 1.71 and a reduction of the displacement of about $79 \%$ (from $17.7 \mathrm{~mm}$ to $3.7 \mathrm{~mm}$ at peak load). Maximum displacement locations shift from the top to the middle of the walls.

The introduction of the ring beam seems to induce a kind of box behaviour in the structure and helps to convey the major damage and stresses in the most resistant part, avoiding in this way to strongly affect the rammed earth walls.

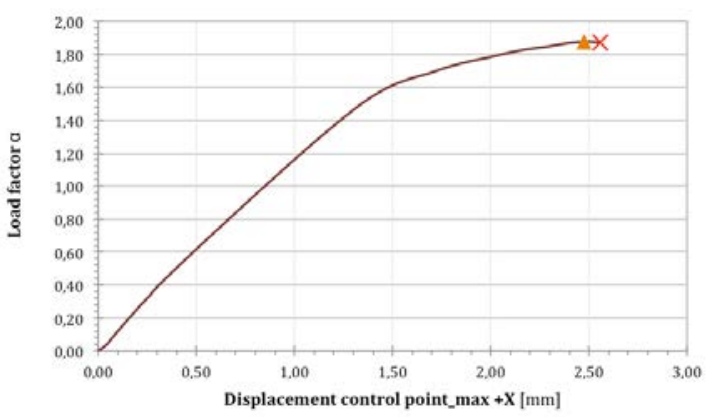

(a)
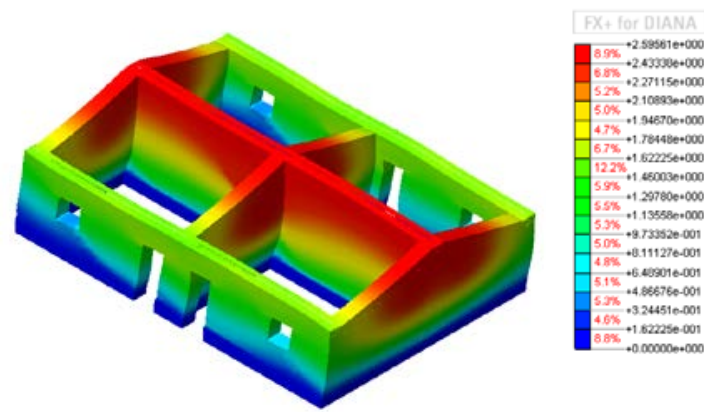

(b)

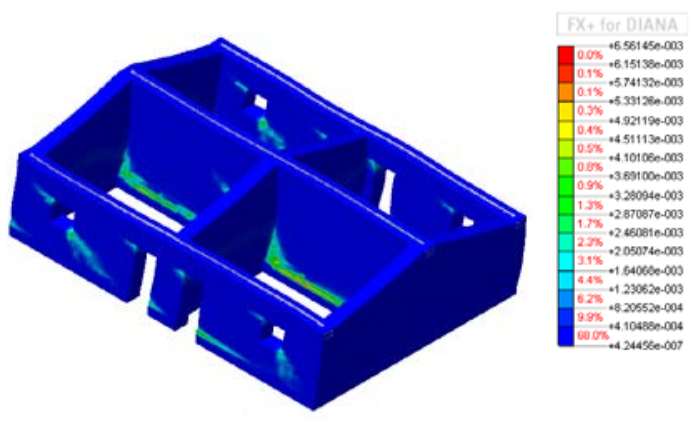

(c)

Figure 7. Pushover results for the $+X$ direction: (a) forcedisplacement curve; (b) displacements at peak load;

(c) tensile principal strains at peak load

\subsection{Comparison of results}

In general, the strengthening solution adopted (ring beam and reinforced coatings on both sides of walls) provides a better seismic behaviour to the structure, preventing early out-of-plane failures, and increases the load capacity of the structure of about $50 \%$ in both directions, namely $52 \%$ in the $+X$ direction, $51 \%$ in $-X$ direction and $49 \%$ in the $Y$ direction, see Figure 9. 
The strengthening influences also the deformed shapes and thus the collapse mechanisms of the structure. Tensile principal strains at peak load indicate that failure associated to the unstrengthened model is about out-of-plane overturning of the external walls, while the strengthened model shows mainly in-plane damage in the walls, which entails a ductile mode that is preferred to the brittle one.

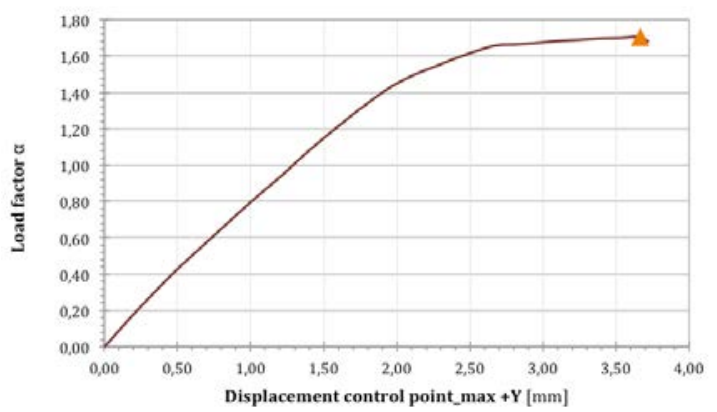

(a)
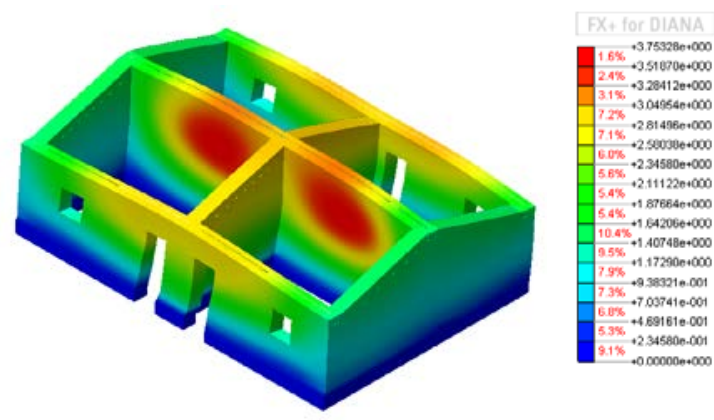

(b)

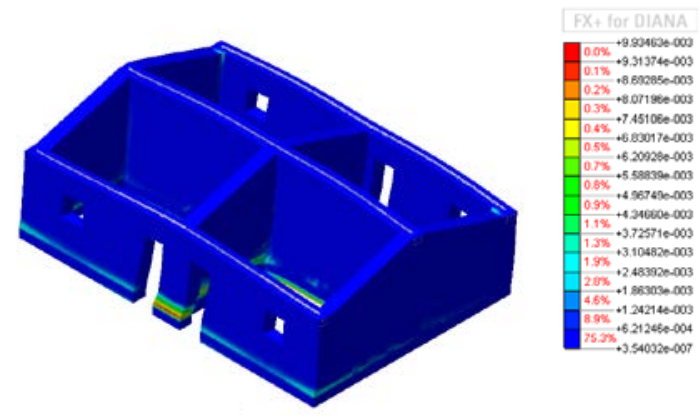

(c)

Figure 8. Pushover results for the $+Y$ direction: (a) forcedisplacement curve; (b) displacements at peak load; (c) tensile principal strains at peak load

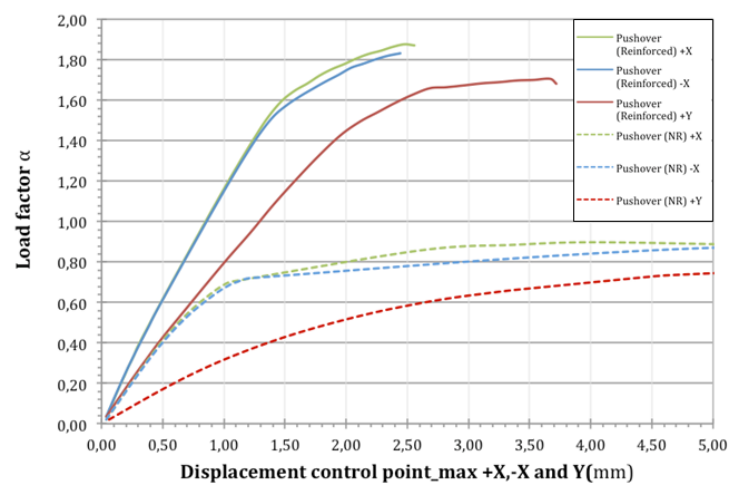

(a)
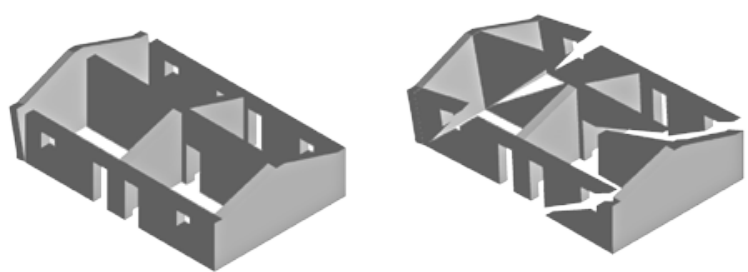

(b)

Figure 9. Pushover results: (a) force-displacement curves; (b) schematic failure modes for the unstrengthened and strengthened models (-X direction).

\section{Main conclusions}

The nonlinear behaviour of rammed earth constructions is an issue that requires deep investigation. The constitutive model adopted here was based on previous applications from the authors, which have provided good comparisons against experimental results.

Due to the lack of suitable experimental information on the performance of the reinforced coatings (TRM technique) adopted for strengthening, a simple modelling approach based on the slight improvement of the tensile properties of materials was adopted here.

The combined strengthening approach adopted (ring beam and TRM) increased the seismic capacity in both directions and allowed to shift the failure mode, generically from brittle out-of- plane to ductile in-plane failure. Accordingly, the location of maximum displacements shifted from the top of walls to its middle high, with important reductions in absolute displacement values, mainly due to the restraining effect of the ring beam. 


\section{Acknowledgements}

This research work was partly financed by FEDER funds through the Competitivity Factors Operational Programme (COMPETE) and by Portuguese national funds through FCT (Foundation for Science and Technology) within the scope of projects POCI-01-0145-FEDER-007633 and POCl-01-0145-FEDER-016737 (PTDC/ECM$E S T / 2777 / 2014)$. The support from grant SFRH/BPD/97082/2013 is also gratefully acknowledged.

\section{References}

[1] Schroeder H., Sustainable building with earth, Springer, 2016.

[2] Houben H., Guillaud H., Earth Construction: A comprehensive guide, CRATerre - EAG, Intermediate Technology Publication, 2008.

[3] Jaquin P.A., Augarde C.E., Gerrard C.M., Chronological description of the spatial development of rammed earth techniques, International Journal of Architectural Heritage, 2008; 2(4): 377-400.

[4] Correia M.R., Varum H., Lourenço P.B., Common damages and recommendations for the seismic retrofitting of vernacular dwellings, Seismic Retrofitting: Learning from Vernacular Architecture - Correia, Lourenco \& Varum (Eds), 2015.

[5] Miccoli L., Oliveira D.V., Silva R. A, Müller U., Schueremans L., Static behaviour of rammed earth: experimental testing and finite element modelling, Materials and Structures, 2015; 48: 3443-3456.

[6] Bui Q.B., Hans S., Morel J.C., Do A.P., First exploratory study on dynamic characteristics of rammed earth buildings, Engineering Structures, 2011; 33: 3690-3695.

[7] ICOMOS/ISCARSAH Committee, ICOMOS charter - Principles for the analysis, conservation and structural restoration of architectural heritage, 2003.

[8] Librici C., Modelling of the seismic performance of a rammed earth building, MSc Dissertation, University of Minho, 2016.
[9] TNO DIANA, User's manual, Release 9.6, 2015.

[10] Silva R.A., Oliveira D.V., Miccoli L., Schueremans L., Modelling of rammed earth under shear loading, 9th International Conference on Structural Analysis of Historical Constructions, 2014; 12 pp. 